\title{
O MÉTODO DE ENSINO DA LEITURA E DA ESCRITA CONCRETIZADO NO MÉTODO LIÇÃO DE COISAS
}

\author{
Cláudia Maria Mendes Gontijo*
}

RESUMO: Este trabalho é parte de um estudo mais amplo, com o objetivo de investigar a história da alfabetização no Espírito Santo (1870 a 1920). Tem por finalidade analisar o método de ensino da leitura e da escrita concretizado no método lição de coisas de Norman Calkins, traduzido por Rui Barbosa, e sua adoção no Espírito Santo por meio do Regulamento da Instrução Pública de 1882. Conclui que a adoção desse método se ancorava na ideia de que a reforma educacional, essencial para a renovação da sociedade e dos seres humanos, se faria pela mudança dos métodos e dos mestres. Defende, ainda, que a sua adoção foi essencial para ajudar a sustentar, no Espírito Santo, a crítica aos antigos métodos de soletração e ao método mútuo.

Palavras-chave: Alfabetização. Método Lição de Coisas. Leitura. Escrita.

\section{THE METHOD OF TEACHING READING AND WRITING CONCRETIZED IN THE OBJECT LESSON METHOD}

ABSTRACT: This work is part of a broader study that investigates the history of alphabetization in the state of Espírito Santo (1870-1920). It analyzes the method of teaching reading and writing concretized in the object lessons by Norman Calkins, translated by Rui Barbosa, and its use in Espírito Santo through the Regulation of Public Instruction of 1882. It concludes that the use of such a method believed in the idea that the educational reform, essential to renew society and the human beings, would be based on the change of methods and teachers. It advocates that this use was essential to help and support the critics to the old methods of spelling and the mutual method in Espírito Santo.

Key words: Literacy. Object Lesson Method. Reading and writing.

\section{LA MÉTHODE ENSEIGNANT À LIRE ET À ÉCRIRE CONCRÉTISÉE DANS LA LEÇON DE CHOSES}

RÉSUMÉ: Ce travail fait partie d'une étude plus ample visant à examiner l'histoire de l'alphabétisation dans l'état d'Espírito-Santo (1870 à 1920). Il analyse la méthode enseignant à lire et à écrire concrétisée dans la leçon de choses de Norman Calkins, traduit au Brésil par Rui Barbosa, et son adoption dans l'état d'EspíritoSanto au moyen du Règlement d'Instruction Publique de 1882. Il conclut que

Doutora em Educação e professora do Departamento de Linguagem, Cultura e Educação da Universidade Federal do Espírito Santo (ufEs).E-mail: clammg@terra.com.br 
l'adoption de cette méthode s'ancrait dans l'idée de ce que la réforme éducationnelle, essentielle au renouvellement de la société et des êtres humains, passerait par le changement des méthodes et des maîtres. Il défend encore que son adoption a été essentielle pour aider à soutenir la critique des anciennes méthodes alphabétiques et à la méthode d'enseignement mutuel dans l'état d'Espírito-Santo.

Mots-clefs: Alphabétisation. Leçon de choses. Lecture. Écriture.

\section{Introdução}

$\mathrm{P}$ esquisas desenvolvidas, no final da década de 1980 e na década de 1990, sobre a produção de conhecimento no campo da alfabetização (Soares, 1989; Soares \& Maciel, 2001) indicaram a existência de poucos estudos nacionais que visaram a abordar a alfabetização numa perspectiva histórica. Essa constatação provocou, na década de 1990 e no início de 2000, o surgimento de estudos com essa finalidade (Mortatti, 2000; Trindade, 2004; Scocuglia, 1997; Silva, 1998; Bertoletti, 1997; Maciel, 2001; Mello, 2002; Santos, 2001). Desse modo, identificamos uma produção acadêmica incipiente, dispersa e ainda não analisada, que fornece elementos para pensar como essa abordagem vem sendo construída.

Assim, a partir de uma investigação pouco sistemática dos estudos acadêmicos (teses e dissertações), verificamos o seu predomínio nas análises dos métodos e cartilhas que preponderaram durante determinadas épocas na alfabetização de crianças ou de jovens e adultos. Encontramos ainda estudos que se dedicaram a discutir políticas de alfabetização de jovens e adultos, que se concretizaram em campanhas adotadas em alguns Estados brasileiros, e um estudo que analisa os discursos político e religioso sobre a alfabetização.

Os estudos que visam a abordar a alfabetização na perspectiva histórica têm sido elaborados por pesquisadores das áreas da Educação, da Linguística e da História. Por isso mesmo, as abordagens teórico-metodológicas e os aspectos focalizados nas análises também são variados. Outro dado importante é que os poucos estudos mais sistematizados, que tomaram períodos históricos mais longos (Mortatti, 2000; Trindade, 2004), estão centrados na análise das polêmicas e debates suscitados em decorrência do uso dos métodos sintéticos e analíticos e das cartilhas.

No estado do Espírito Santo, não tivemos conhecimento de estudos que abordaram a alfabetização numa perspectiva histórica. Acreditamos que essa abordagem do problema seja fundamental para que possamos compreender o presente ainda marcado por altos índices de analfabetismo e de analfabetismo funcional e, certamente, para pensar o futuro. Como assinala Graff (1994, p. 45), “(...) o estudo apropriado da experiência histórica da alfabetização tem mais que apenas um interesse de antiquário; ele tem muito a dizer para análise e formulação de políticas no mundo em que hoje vivemos". 
Este texto tem por objetivo discutir o movimento de adoção no Espírito Santo, no Regulamento da Instrução Pública de 1882, do método Lição de Coisas e analisar o sistema de ensino da leitura e da escrita concretizado neste método. Primeiramente, é necessário apontar como compreendemos os documentos analisados, porque o corpus de análise, neste artigo, é constituído por textos impressos ou manuscritos. Segundo Bakhtin (1992, p. 329), o texto escrito ou oral é um dado primário de análise de todas as disciplinas e, de modo geral, “(...) de qualquer pensamento filosófico humanista". Assim, para o autor, o texto "(...) representa uma realidade imediata (do pensamento e da emoção), a única capaz de gerar essas disciplinas e esse pensamento. Onde não há texto, também não há objeto de estudo e de pensamento" (idem, ibid.). Dessa forma, o ponto de partida de uma abordagem histórica da alfabetização, como de qualquer outra disciplina ou pensamento filosófico, é o texto.

Assim, o texto (escrito) utiliza o sistema da língua para produzir significados. Como unidade de significação, é um produto de criação ideológica e, então, só pode ser compreendido em relação com a sociedade, ou seja, com o contexto sóciohistórico e ideológico em que foi produzido. Ao buscarmos compreender os textos em relação com o contexto de produção ou social, conhecemos e compreendemos o ser humano numa perspectiva dialógica. Portanto, o ato de compreensão também é de natureza dialógica. Conforme sugere Barros (1997, p. 30), o ponto de partida de Bakhtin é a colocação do texto "(...) como fulcro, como lugar central de toda investigação sobre o homem" e sobre os fenômenos sociais e culturais que, por sua natureza, são criações humanas.

Ao tratar a alfabetização em uma perspectiva histórica e tomando o texto como objeto de estudos, as ideias de Bakhtin (1992) de dialogismo, de diálogos entre discursos, são fundamentais. Nessa perspectiva, o texto é concebido “(...) como um 'tecido de muitas vozes', ou de muitos textos ou discursos, que se entrecruzam, se completam, respondem umas às outras ou polemizam entre si no interior do texto" (Barros, 1997, p. 34; grifo da autora). Como acentua Burke (2000, p. 267), a abordagem histórica de um problema deve levar em conta as várias vozes que o formam, ou seja, ela tem que ser "polifônica". Usando os termos desse autor, "(...) tem de conter em si mesma várias línguas e pontos de vista, incluindo os dos vitoriosos e vencidos, homens e mulheres, os de dentro e os de fora, de contemporâneos e historiadores".

\section{Reforma dos mestres e dos métodos}

Os Regulamentos de 1873 e 1877 da província do Espírito Santo mantinham como métodos oficiais a serem adotados nas escolas públicas o simultâneo ${ }^{1}$ e o simultâneo e misto, ${ }^{2}$ respectivamente. Nesse sentido, a possibilidade de introdução de 
outros métodos para o ensino da leitura e da escrita só ocorreu na década de 1880, sob a vigência do Regulamento de 1882 e com a vinda de Silva Jardim ao Espírito Santo para divulgar o método João de Deus. ${ }^{3}$ Nesse mesmo ano, o jornal A Província do Espirito-Santo publicou uma série de artigos em favor do método Lição de Coisas e o Regulamento de 1882 definiu sobre a sua adoção pelas escolas públicas.

No primeiro artigo veiculado no jornal em defesa desse método, o redator criticava a situação do ensino primário naquele Estado e apontava:

A escóla è um templo da moral individual e da moral social. Ella deve ser um prolongamento do affavel e interessado conselho do lar. O espirito infantil é uma borboleta inquieta; indeciso, traqüinas, desconfiado, doudo de liberdade, sente-se tão constrangido nos limites de nossa escóla quanto o condemnado no fundo da enxovia. (A Provincia do Espirito-Santo, 1882a, p. 2).

Nesse sentido, o texto criticava a escola tradicional e o modelo de ensino por ela adotado (o ensino mútuo ${ }^{4}$ ), que impedia as crianças de se desenvolverem plenamente, pois não respeitavam o seu desenvolvimento natural. Segundo o mesmo artigo, os mestres submetiam os alunos a castigos físicos para despertar a sua atenção. Entretanto, é importante salientar que um dos méritos do ensino mútuo foi de não prever os castigos físicos como penalidade para os "maus alunos". O redator criticava o uso desse tipo de castigo, mencionava que os professores protestavam contra aqueles que reivindicavam o seu fim, pois julgavam que eram necessários à educação da infância, e assinalava que a própria família era cúmplice da atitude dos professores.

Na opinião do redator, os castigos físicos que pretendiam impor a aprendizagem e obter a atenção dos alunos à força influenciavam os resultados negativos do ensino primário. Afirmava ele: “(...) apenas os pobres chegam a soletrar mal, depois a arrastar indigestamente umas palavras que elles sabem, á responder umas perguntas banaes sobre religião ou a fazer bestialmente umas contas, cuja applicação mesmo ignoram" (A Provincia do Espirito-Santo, 1882a, p. 2).

Com relação aos castigos físicos, o Regulamento de 1882 proibiu-os definitivamente, no artigo 59 das Disposições Especiais para a escola primária, e estabeleceu penalidade que consistia na suspensão imediata, pela autoridade competente, daqueles professores que descumprissem o preceito legal. O Regulamento estabelecia ainda que os alunos que se mostrassem incorrigíveis deviam ser encaminhados ao delegado literário para que este procedesse à autorização da expulsão dos mesmos. Também no artigo 29 estavam definidos os tipos de castigos disciplinares a que os alunos poderiam estar sujeitos:

$\S 1^{\circ}$ Reprehensão em particular

$\S 2^{\circ}$ Reprehensão em classe 
$\S 3^{\circ}$ Trabalho na escola fóra das horas lectivas

$\S 4^{\circ}$ Privação das palestras e passeios das quintas feiras ficando o alumno retido na casa da escola, durante as duas horas que durar a diversão do outro.

Assim, havia mudanças nos elementos disciplinadores, pois os castigos que redundavam em dor física ou humilhação pública foram eliminados. Nessa direção, podemos dizer que o Regulamento de 1882 representou um grande avanço em relação às práticas até então adotadas, o que não impediu que os professores continuassem a se valer dos castigos físicos e de outros que humilhavam as crianças perante a classe.

O artigo apontava ainda que a ignorância dos estudantes não era causada somente pelas atitudes do professor que reprimiam o espírito e a inteligência infantil, por meio de castigos físicos. A responsabilidade era também do sistema de ensino adotado em todos os graus, que sufocava a inteligência e impunha o ensino religioso nas escolas. Nesse sentido, nas determinações sobre a adoção do método mútuo na Província, previa-se que uma das obrigações do professor era acompanhar os alunos à missa aos sábados ou domingos, cuidando para que se conduzissem com "respeito e reverência, fazendo com q'alternadamente dous dos mais adiantados sirvão de acolytos".

No segundo artigo, publicado no mesmo jornal, sobre o estado atual da instrução pública, o redator continuou o seu discurso centrado em questões relativas aos métodos de ensino e à sua inadequação ao desenvolvimento psicológico da criança. Segundo ele, este seguia o mesmo percurso do desenvolvimento sociológico:

(...) do mesmo modo que a humanidade caminhou sempre do concreto para o abstracto, a creança não póde aprrehender uma ideia sem ser primeiramente tocada pela sensação correspondente que a produz. Procurar ferir-lhe a razão antes de despertar o sentimento é tarefa perfeitamente vão. (A Provincia do Espirito-Santo, 1882b, p. 3)

Entretanto, o sistema de ensino da infância adotado no país, segundo o redator, ao invés de impressioná-la vivamente, por meio do concreto, ensinava primeiro as crianças a balbuciar letras, a reproduzir o alfabeto na ordem em que aprendeu a ouvi-lo, mas sem compreensão. Sendo assim, as crianças não conseguiam aproveitamento real:

Das lettras ás syllabas, das syllabas ás palavras e das palavras á leitura, após um esforço supremo, tudo segue uma marcha diversa do desenvolvimento normal do seu cérebro. Lê materialmente sem entender, sem se aperceber mesmo do que faz. (A Provincia do EspiritoSanto, 1882b, p. 2)

Diante dos males que o ensino abstrato produzia nas crianças, o redator defendia, no terceiro artigo publicado no jornal, a mudança do "systema de ensino" no Império e na província do Espírito Santo. Nessa direção, assinalava que alguns espíritos cultos, cientes das dificuldades e da indiferença dos poderes públicos, vinham 
tentando "(...) medidas generosas, mas que só [deslocavam] o problema". Segundo o redator, o Sr. Abílio, professor primário bastante conceituado,

(...) lembrou de proporcionar á infância alguns livros de educação indubitavelmente muito aproveitáveis, mas que com o vicioso systema á que elles vêm servir, pequenas vantagens poderão offerecer. Leituras úteis mais ou menos acomodadas ás diversas phases do desenvolvimento dos educandos, não obstante todo o seu mérito desapparece aos solavancos da inépcia de seus intérpretes na maior parte das escolas. (Idem, ibid., p. 2)

Nesse sentido, considerava que os livros de leitura de Abílio eram adequados, pois conduziam o ensino do todo para as partes. Segundo ele, antes de dividir qualquer objeto na mente, a primeira coisa que impressiona é o seu todo. Assim, defendia a adoção, na Província e no Império, do método de ensino adotado na América do Norte e na Europa, com resultados satisfatórios, mesmo que essa adoção tivesse planos mais modestos na Província, de acordo com as suas condições financeiras. Para o redator, nos Estados Unidos, a escola promovia a educação da infância de modo satisfatório. Dessa forma, fez uma pequena exposição das bases psicológicas do Méthodo Lição Sobre Couzas, considerado apropriado para trabalhar com as crianças, pois partia do concreto para o abstrato, do todo para as partes.

Em substituição ao anachronico e desacreditado processo, nós teríamos uma disciplina mais compatível com os grandes interesses da humanidade, que proporcionaria a instrucção em doses calculadas, aproveitando todas as aptidões, e facto mais insignificante tirando um ensinamento. (Idem, ibid.)

A adoção do método significaria uma reforma da educação. Entretanto, considerava que o professorado existente na Província e em todo o território nacional não estava em condições de realizar a reforma do ensino e dos métodos de que dependia "(...) a elevação da intellectualidade brasileira" (idem). Não se tratava, portanto, apenas de uma mudança dos livros de leitura, dos compêndios, das gramáticas, segundo o redator; tratava-se de uma reforma que dependeria do próprio professor.

É mister que, no desempenho de sua árdua missão [...] discuta com seus jovens discipulos mil objectos, discriminando-os, indicando-lhes as qualidades proprias de cada um; que saiba em todas as suas narrações ferir o sentimento da curiosidade, tão freqüente na creança, pela vida da phrase, pela graça do conto, pelas symphatias do assumpto. (A Provincia do Espirito-Santo, 1882b, p. 3)

Feita a reforma do pensamento do magistério, a escola se tornaria “(...) um pequeno musêu da vida, os livros, os compendios serão simples necessarios e auxiliares" (idem, ibid., p. 3). Dessa maneira, de acordo com a ideia recorrente no Brasil, o redator reforçava que a reforma da educação e a melhoria dos seus resultados dependeria da mudança dos métodos e dos mestres. 
É importante comentar um aspecto presente no discurso do redator, relativo ao trabalho do professor Abílio César Borges (Barão de Macahubas). Este, conforme assinala Saviani (2007, p. 139), foi “(...) o criador do famoso Ginásio Baiano, em Salvador, depois, do Colégio Abílio da Corte, no Rio de Janeiro". Ele integrou o movimento de difusão de materiais pedagógicos, introduzindo "(...) nas escolas aparelhos escolares como os globos de horas relativas de Juvet, o globo de Perce, o telúrio de Mac-Vicar, além de outros por ele mesmo inventados, como foi o caso do aritmômetro fracionário" (Saviani, 2007, p. 139).

O uso desses materiais dependia, na opinião do Barão de Macahubas, da adoção de um novo método de ensino. Nesse sentido, ele também considerava o método Lição de Coisas apropriado à renovação da escola. Saviani (op. cit., p. 139), ao analisar a introdução do método intuitivo no município da Corte, considera que estava em jogo a necessidade de adoção de um método de ensino

(...) entendido como uma orientação segura para a condução dos alunos, por parte do professor, nas salas de aula. Para tanto, foram elaborados manuais segundo essa diretriz que modificava o papel pedagógico do livro, que, em lugar de ser um material didático destinado à utilização dos alunos, se converte em "material essencial para o professor, expondo um modelo de procedimentos para elaboração de atividades que representem a orientação metodológica geral prescrita".

Os textos publicados no jornal A Província do Espirito-Santo corroboram o que foi dito pelo autor, pois, como vimos, o redator estava consciente de que o magistério não estava em condições de proceder à necessária reforma no ensino. Desse modo, o método Lição de Coisas era apropriado, porque continha as orientações necessárias aos professores para que pudessem levar as crianças a aprenderem por si mesmas. Valdemarim (2004, p. 119), ao examinar o segundo manual Primeiras lições de coisas, de Norman Allison Calkins, considera-o um “(...) marco significativo da tentativa de implantar o método de ensino intuitivo no ensino brasileiro, que remonta ao decênio de 1880". Menciona que ele expressa ainda “(...) a pretensão de adotar um método didático consoante com a renovação pedagógica em curso na Europa e nos Estados Unidos da América, cujos efeitos poderiam ser irradiados para toda a sociedade, almejada nas últimas décadas do Império" (idem, ibid.). Esse manual, dirigido aos pais e aos professores, continha uma exposição sobre o conteúdo a ser ministrado e as prescrições sobre a forma como deveria ser transmitido ao aluno. A mesma autora aponta:

O discurso político e educacional produzido nesta época estabelece estreitos vínculos entre as propostas de inovação metodológica e a difusão do ideário liberal republicano, destacando-se a utilização das "lições de coisas" ou método intuitivo como estratégia de intervenção na sala de aula, lócus privilegiado da instrução e da mudança das práticas pedagógicas, adequando a escola ao projeto político modernizador. (Idem, ibid.) 
O Regulamento de 1882 expressava essa pretensão de renovação pedagógica e definiu, no artigo 10, que as escolas elementares professariam:

$\S 1^{\circ}$ Leitura.

$\S 2^{\mathrm{o}}$ Noções de geometria prática - dezenho linear.

$\S 3^{\circ}$ Calligraphia.

$\S 4^{\circ}$ Exercicios de intuição ou noções de cousas, acompanhando os exercícios de leitura e escripta e as explicações de geometria e de dezenho.

$\S 5^{\circ}$ Contabilidade. Quatro operações fundamentaes do calculo sobre inteiro e fracções. Systema metrico decimal.

$\S 6^{\underline{0}}$ Rudimentos de geographia phisica da provincia.

$\S 7^{\circ}$ Costuras simples nas aulas de meninas. (Grifo nosso)

Além de definir o método e o conteúdo a ser trabalhado, o Regulamento apresentava algumas orientações quanto à escolha dos livros de leitura. Eles deviam conter, preferencialmente, "estampas" para melhor aplicação das "noções de couzas" e tratar da fauna e da flora brasileira e espírito-santense, ou de métodos agrícolas. O professor tinha obrigação ainda de tornar o ensino prático:

(...) fazer conhecer os objectos, as suas qualidades e sua organização e partindo sempre do concreto para o abstracto; deve prescindir de perturbar a intelligencia da criança com o estudo prematuro de muitas regras e deve procurar desfrutar-lhe a atenção, sem fatigal-a. Usará de uma linguagem chã, mas clara e preciza, que familiarize a intelligencia do alumno com o assumpto.

No capítulo que tratava sobre o ensino suplementar, o Regulamento estabelecia que o ensino elementar limitar-se-ia à obrigação de frequência às escolas públicas. O ensino suplementar era livre. Nesse sentido, mesmo que a educação fosse propagada como a base da reforma da sociedade, ela deveria ser, para a maioria da população, apenas a elementar, ou seja, aquela que garantisse a aprendizagem dos rudimentos da leitura, escrita, aritmética, geografia, entre outras.

As aulas do ensino primário deveriam, de acordo com o Regulamento de 1882, ser divididas em duas sessões de duas horas, uma para os alunos menores e outra para os alunos maiores. Haveria aulas nas escolas todos os dias, exceto nas quintasfeiras, quando os professores reuniriam os alunos para passeios pelo campo, "(...) aproveitando os objectos que se lhes [oferecessem] a vista para dar aos meninos explicações ligeiras sobre história natural, cosmographia ou agricultura". Se não tivessem condições de realizar passeios campestres, os professores poderiam reunir seus alunos nas escolas e fazê-los cantar o Hino Nacional ou outros hinos patrióticos e ensinar música àqueles que se mostrassem interessados. Também deveriam incentivar a recitação de poesias nacionais ou outras que ensinassem noções sobre os 
deveres do homem como membro da família e da sociedade. Nas escolas agrícolas, era fundamental tratar de fatos e métodos da lavoura apropriados ao lugar.

Nos artigos publicados no jornal A Província do Espirito-Santo, o redator defendia o ensino primário científico que, segundo ele, era considerado por muitos como uma novidade inaceitável. Sobre esse ensino, assim se manifestou:

Tem por base a educação positiva. Comprehende-se para o homem moderno o dever e a necessidade de estar ao nível dos reclames do seu tempo e ter uma intuição geral da vida, comprehende-se ainda a superfluidade d'estes indigestos acervos de conhecimentos que pódem quando muito lisongear a vaidade, mas muito pouco servem a intelligencia. (A Provincia do Espirito-Santo, 1882c, p. 2).

O redator apontava ainda que a educação positiva tinha como vantagens uniformizar o cabedal intelectual distribuído pelo Estado e dar noções indispensáveis à conduta em sociedade. Para ele, depois da divisão das ciências efetuada por Comte,

(...) os phenomenos de todas as ordens que antes se achavam dispersos, sem laço commum entre si, que determinasse sua disposição methodica, a confusão que existia no domínio de todas as sciencias, tudo acomodou-se em suas respectivas ordens, e os factos mais simples como os mais complicados encontram sua explicação immediata na sciencia respectiva. (Idem, ibid.)

Nesse sentido, considerava que, mesmo não sendo possível ensinar a lei geral das ciências, a sua classificação hierárquica deveria ser aproveitada para dirigir a educação e deduzir os conhecimentos mais fáceis de serem ensinados.

\section{O método Lição de Coisas e o ensino da leitura e da escrita}

O método Lição de Coisas, de Norman Calkins, foi traduzido por Rui Barbosa, que também compartilhava com o redator do jornal A Província do Espirito-Santo a expectativa de que ele ajudaria a solucionar os problemas da educação. Tomaremos, para contextualização e análise das concepções que norteiam o método, o prefácio de Lourenço Filho à obra traduzida e, em seguida, discutiremos as partes do manual que concretizam o método de ensino da escrita e da leitura.

Segundo Lourenço Filho (1956, p. xvıII), o Método Intuitivo ou Lição de Coisas representou uma verdadeira revolução no ensino. Nesse sentido, ele veio contrariar não apenas um método, mas a organização do ensino configurada pelo método mútuo ou monitorial: “(...) adotado especialmente como expediente de economia, por ele um mestre ensinava a dez 'decuriões', que, por sua vez, deveriam ensinar a dezenas de condiscípulos”. De acordo com esse mesmo autor, a obra de Calkins concretizava as ideias de Pestalozzi por meio de um manual dirigido aos professores. Porém, como aponta Lourenço Filho (1956, p. xxıx), 
(...) havendo partido do ensino intuitivo, tal como o desejava Pestalozzi, Calkins a ele se adiantou, ou lhe desdobrou o pensamento, até chegar a expor, por muitos pontos, claros princípios do ensino ativo. Apóia-se, para isso, em Froebel, cujas teorias, apoiadas num vago "simbolismo", haviam, no entanto, por influência de Rousseau, posto em voga as expressões de "atividade própria do aluno", "poder criador" e "auto-expressão".

A obra Lições de Coisas é composta de várias partes. Na primeira, intitulada "Primeiras lições de coisas", são tratados os princípios fundamentais do método e, em seguida, a educação doméstica, que visa a "educar os sentidos". Na segunda parte, denominada "Ensino escolar: lições preambulares para cultivar as faculdades da observação e uso das palavras", é ensinado como trabalhar formas, cores, números, quatro operações, desenho, escrever, tempo, som, leitura elementar, qualidade das coisas etc. O trabalho de tradução efetuado por Rui Barbosa, segundo Lourenço Filho (1956), não foi simples, pois muitas adequações foram necessárias. Entre elas, de acordo esse autor, toda a parte que trata dos sons da linguagem é de lavra de Rui Barbosa, pois, conforme o este, não se podia aproveitar as orientações elaboradas para a língua inglesa.

Como dito, analisaremos as orientações para se trabalhar o escrever, o som e a leitura elementar, lembrando, dessa forma, que a parte referente ao som é de autoria de Rui Barbosa. Consideraremos, na análise, a ordem em que os textos aparecem no livro. Com relação ao escrever, o texto inicia afirmando a sua importância. Enfatiza que o ensino deve começar por traçar letras e palavras, cada um na sua pedra ou no quadro negro. Assim que as crianças conseguirem decifrar as letras e as palavras, é necessário trabalhar o silabário e, em seguida, a escrita propriamente dita, "(...) versando essas sobre as letras minúsculas, ordenadas segundo a sua maior ou menor simplicidade, depois sobre palavras simples, depois sobre os caracteres maiúsculos, ao cabo sobre proposições inteiras" (Calkins, 1956, p. 366). Os alunos deverão iniciar o trabalho de escrita em pedra e só depois irão usar papel. Quando estiverem no terceiro livro de leitura, escreverão "limpamente o seu nome, a data e palavras singelas, coordenadas em orações" (idem, ibid.). Não há definição de livros para serem utilizados, mas o texto aponta que existem muitos livros adequados e desenvolvidos para auxiliar a aprendizagem do mecanismo da escrita.

Com relação ao estudo do som, o texto menciona, inicialmente, a educação do ouvido. Segundo o exposto, os órgãos dos sentidos são portas "por onde o saber nos penetra no entendimento". Logo, eles devem ser exercitados desde o nascimento e, por isso, na primeira parte, são apresentadas experiências que a família pode utilizar para desenvolvê-los. O ouvido é muito importante, porque é por meio dele que reconhecemos os sons vindos do exterior. Se a criança não ouvir bem, não falará bem. Assim, será impossível fazer com que leia bem. Por isso, é necessário fazer com que ela pronuncie bem todos os sons da voz humana.

Após versar sobre a importância de se trabalhar o ouvido, indicam-se alguns exercícios para distinguir sons. No primeiro, as crianças devem distinguir sons de 
objetos; em seguida, começam a distinguir os sons vocálicos. No segundo passo, são trabalhados exercícios para comparar e classificar sons. Assim, inicialmente, a criança é levada a distinguir e comparar sons que estão presentes no ambiente (de atrito, de animais etc.). Somente após essa fase, é iniciado o trabalho com os sons da linguagem humana. Com relação a este último, o primeiro passo é levar as crianças a distinguir os sons da fala por meio da repetição, após a pronúncia pelo professor de palavras conhecidas, compostas de uma ou duas sílabas. Depois desse exercício, deverão ainda repetir palavras, alongando o som vocálico e, a seguir, com atenção nos sons consonantais. Entretanto, nesse momento, não há nenhuma tentativa de aliar esses sons aos seus correspondentes gráficos.

Após esse trabalho, segundo prescrito, as crianças serão levadas a distinguir os sons das palavras, por meio da repetição de vocábulos compostos com sons simples. Somente no terceiro passo, os sons serão associados às letras. Assim, são ensinadas aquelas que correspondam às consoantes e palavras que possam ser formadas com as letras aprendidas. A pronúncia de cada letra é detalhada para que o professor aprenda a articulá-la de modo apropriado e ensine adequadamente a seus alunos. Elas são ensinadas considerando uma ordem crescente de dificuldades: da mais simples para a mais complexa (v, f, j, t, d, b, p, l, k, q, c). Após o ensino dessas letras simples, passa-se para as compostas (ch, $\mathrm{x}$, çe etc.). É interessante notar que há uma preocupação em ensinar que um som pode ter diferentes correspondentes gráficos. Conforme escrito no manual,

(...) o passo primordial no ensino dos elementos phonicos da linguagem consiste em costumar o ouvido a discriminal-os, e o subseqüente em habituar o órgão da falla a produzil-os. Só havendo caprichoso esmero nesses dois passos, se apurará a salutar influência desse ensino na educação elementar. (Calkins, 1956, p. 407)

Quanto à leitura elementar, no manual são feitas críticas e comentários sobre os métodos de leitura existentes, entre eles os métodos ABC e fônico. Com relação ao primeiro, estipula:

Consiste este velho, demorado e tedioso método em ensinar primeiro o nome de cada uma das vinte e seis letras, depois a combinação delas em sílabas sem sentido, de dois e três caracteres, mais tarde a sua junção em palavras de duas, três e mais sílabas. Da significação das palavras não se faz nenhum caso. (Idem, ibid., p. 408-409).

Nesse sentido, considera que o ensino das palavras é mais apropriado, porque permite concretizá-las por meio dos objetos e imagens. O método ABC é abstrato e não permite essa concretização.

O método fônico, segundo o manual, tem diferentes formas, mas também não possibilita partir do concreto ao abstrato. De acordo com Calkins (1956, p. 412), independente das maneiras como tem sido proposto, consiste basicamente em "(...) encetar o ensino, não pelo nome das letras, mas pelos seus sons, e, conhecidos estes, 
solicitar as crianças a aplicá-los à leitura das palavras". Nesse sentido, critica o método e aponta que o seu principal problema é o caráter pouco "natural e antifilosófico do seu sistema", pois a forma natural de se ensinar à criança é por intermédio das unidades da linguagem, que são as palavras.

A linguagem depende do pensamento; as palavras são símbolos de ideias. Nem as letras, nem os sons são elementos do pensamento. As letras são elementos da forma das palavras; os sons, simples elementos dos sons harmônicos da palavra; mas nenhum desses elementos constitui a unidade da linguagem. O verdadeiro ponto de partida no ensino da leitura está em tomar a ideia com o seu sinal como um só todo. Subsequentemente, então se analisará o sinal, decompondo-o, e se aprenderão os elementos, quer do seu som, quer da sua forma. (p. 414)

Após tecer críticas aos métodos de ensino da leitura, o manual propõe o método "objetivo" ou "intuitivo" de ensinar a ler. Esse seria mais apropriado, pois dirige “(...) a atenção dos alunos para algum objeto, cujo aspecto, nome e uso lhes sejam familiares" (p. 422).

O método intuitivo ou objetivo de leitura é dividido, de acordo com o manual, em fases: na primeira, as lições são compostas por palavras e, na segunda, é utilizado o livro de leitura e, por isso, essa parte do manual é denominada Leitura de Livros. Desse modo, os livros começam a ser manuseados apenas na segunda fase. A primeira deve ser construída pelo professor, seguindo as orientações contidas no manual, mas usando palavras conhecidas e utilizadas pelas crianças.

Na primeira fase, destaca a necessidade de ensinar o discípulo a distinguir o objeto, a sua imagem e a palavra que o nomeia. Assim, deve-se mostrar o objeto, a sua imagem (desenho impresso ou feito pelo professor na lousa) e a palavra. Procedendo dessa maneira, o professor pode ensinar muitas palavras antes de iniciar o estudo dos sons ou das letras de cada uma. Dessa forma, as crianças aprendem as palavras como símbolos dos objetos e dos seus nomes falados. $\mathrm{O}$ manual sugere aos professores que, primeiro, ensinem nomes e, só mais tarde, vocábulos que indiquem qualidades ou ações. Nessa perspectiva, ensinar a ler os nomes é essencial para que a criança memorize a sua forma escrita e, também, necessário, porque há correspondentes concretos que podem ser manuseados e, depois, expressos por meio de imagens. As demais classes de palavras, ou, como dito no manual, as palavras pequenas que fazem a articulação entre as frases só serão ensinadas quando o ensino de frases e sentenças o exigir. Segundo ainda o manual, o ensino da leitura é fácil, pois o mestre só precisa utilizar o quadro negro. De acordo com o manual, os passos da leitura pelo método "objetivo" ou "intuitivo" são:

Primeiro passo - Ensinai a distinguir pelo aspecto palavras já conhecidas ao ouvido como sinais de objetos, qualidade e ações.

Segundo passo - Ensinai a decompor as palavras nas suas letras. Debuxe o menino a palavra na pedra em caracteres de imprensa, aprendendo assim as figuras e nomes das letras, bem como sua ordem no vocábulo. 
Em vez disto, pode o segundo passo consistir no ensino dos sons das palavras.

Terceiro passo - Ensinai a análise das palavras nos seus sons elementares, sem atender às letras que os representam.

$\mathrm{Ou}$ (conforme a alternativa preferida no passo anterior) ensinai, como terceiro passo, a decomposição do vocábulo nas suas letras. A condição dos alunos determinará a escolha do mestre quanto à prioridade entre os sons e as letras.

Quarto passo - Fazei com que o aluno pronuncie a palavra, lendo-a, destaque-lhe depois os sons e soletre-a.

Quinto passo - Ensinai os discípulos a ler palavras em grupo como: “Meu chapéu”, “Um pião novo", "Um bom menino", "Atirar o pião" etc.

Empregai-as também, formando breves sentenças, verbi gratia: "Sei atirar o meu pião", “Tenho um chapéu" etc.

Por meio da aplicação exata desses passos, seria possível, então, que as crianças associassem a palavra a seu todo (som, letra, objeto e ideia). A escolha das palavras a serem utilizadas no ensino de leitura deve observar duas indicações contidas no manual: a) devem ser palavras usadas nas conversações infantis; b) devem ser escolhidas de modo que seja possível mostrar às crianças os objetos que elas significam e suas imagens.

Na segunda fase - leitura de livros -, conforme Calkins (1956), ao desenvolver a leitura com os alunos, o professor deve certificar-se de que as crianças discernem o texto escrito e as palavras novas, mediante os passos de leitura da primeira fase. $\mathrm{O}$ autor define passos e métodos que, de acordo com ele, permitem “(...) a transição entre o ensino por exercícios sobre coisas, com o auxílio do quadro preto, e o ensino por compulsação dos livros" (Calkins, op. cit., p. 433). No primeiro, deve-se ensinar a criança a manusear o livro, a passá-lo para um colega, a localizar uma lição e a separar grupos de palavras. De acordo com o autor, essa etapa “(...) deve durar uma semana, uma vez por dia, enquanto os discípulos estão aprendendo a ler as proposições no quadro preto" (idem, ibid.).

No segundo passo, o professor deve escolher um livro e lições que contenham termos conhecidos das crianças.

Dispondo em colunas, no quadro preto, as palavras desta lição, distribuindo anàlogamente às lições de soletrar, cada sentença em uma coluna, de modo que se leia de cima para baixo. Então pronunciem os alunos as palavras já conhecidas. Depois, o mestre lhe ensinará as novas como na primeira fase. Depois chamará os alunos a lerem todas as palavras da coluna e a descobrirem o que elas significam. De igual modo, se procederá, nas lições, com as sentenças dispostas em colunas. (Idem, ibid.)

Após esse trabalho, as sentenças deverão ser escritas nas pedras, aproveitandose toda a sua extensão, devendo os alunos ler duas ou três vezes. Segundo o autor, essas atividades preparam o aluno para a leitura da mesma lição no livro. Esta leitura iniciase pela busca da lição estudada na pedra e, em seguida, pela busca das sentenças na 
lição. No decurso das atividades, os alunos aprenderão a ler uma lição inteira. É preciso ainda cuidar para que os alunos leiam "os pensamentos do modo como os exprimiriam falando".

No terceiro passo, o professor deverá escolher vocábulos difíceis de uma lição e ensiná-los no quadro negro. Logo após, os alunos deverão procurá-los na lição competente. Depois de solicitar que os alunos leiam as palavras, eles devem ser induzidos a descobrir "(...) o que se exprime na primeira linha, ou sentença; depois o que se diz na segunda linha, e assim por diante com a lição tôda". Cada sentença deve ser lida por três ou mais alunos, e o professor deve levar o aluno a discuti-la. Esses exercícios visam a ensinar a ler a lição. $O$ autor aconselha o professor a não ler para o aluno, pois essa atitude forma maus hábitos, visto que leva o aluno a esperar a intervenção do professor e não tentar ler com independência, pelos seus próprios meios.

$\mathrm{Na}$ quarta etapa, o professor mandará os alunos abrirem os livros para que leiam cada palavra de um parágrafo, começando pela última, de modo que eles se habituem a ler as palavras de uma lição antes de conhecer o conteúdo nela tratado.

No quinto passo, o professor deverá escolher uma lição com palavras menos conhecidas pelas crianças e levá-las a pronunciá-las do modo como exprimiriam o pensamento. Em seguida, deverá passar para exercícios sobre o entendimento das sentenças e de leitura, que deve ser realizada "com tom de voz natural e desembaraçado". Caso o aluno não consiga desenvolver a leitura desse modo, ele deverá repetir a atividade até que consiga fazê-lo. Em algumas situações, o professor deve ler e, em seguida, chamar os discípulos para que façam a leitura de acordo com o modelo mostrado.

A partir do sexto passo, os exercícios devem privilegiar o sentido das palavras e sentenças, bem como a exposição pelos alunos dos elementos importantes do texto lido. Os alunos devem ser levados a copiar palavras e escrever sentenças de modo a demonstrar que compreendem seu sentido. Além disso, eles devem substituir uma palavra na frase por outra e encontrar grupos de palavras que podem ser lidas como sentenças etc. Finalmente, o autor reitera:

Durante os exercícios de leitura, observai a maior persistência em acostumar o aluno a discernir ao primeiro aspecto os vocábulos, interpretar o sentido às palavras que a compõem, e, afinal, lê-la desembaraçadamente, com a voz natural a um colóquio familiar e correto. (Calkins, 1956, p. 437; grifos do autor)

Após o professor seguir esses passos, ele deverá iniciar o processo baseado em exercícios de conversas. Assim, durante todo o curso de leitura, o professor deverá levar os alunos a responderem às questões na seguinte sequência:

Primeiro: O que diz esta sentença? Este período? Este parágrafo?

Segundo: Como exprimireis o que aí se diz? 
Em torno dessas duas questões pode o mestre agrupar tudo o que de atenção é digno, na leitura ensinada às crianças. (Idem, ibid., p. 439)

Segundo Calkins (op. cit.), a soletração é importante para aprender a escrever. Para aprender a ler, ela não é importante, pois, soletrando, a criança não adquire naturalidade na leitura. Entretanto, a leitura facilitará a soletração. Desse modo, as crianças não devem ser levadas a soletrar enquanto seus ouvidos não se acostumarem com os vocábulos inteiros. "As lições iniciais de soletração, dadas enquanto o aluno se habilita para ler palavras familiares, devem dirigir-se, estampando o professor em letra redonda, no quadro preto, expressões familiares, e ensinando-as pelo seu aspecto, e não de ouvido (Calkins, 1956, p. 439)".

Os alunos aprenderão a soletrar escrevendo, em suas ardósias, letras de imprensa copiadas do quadro negro e, depois, dos livros. Assim que aprenderem a escrever, aprenderão a soletrar, escrevendo palavras nas ardósias. Os exercícios consistem em o professor dizer uma palavra, a criança repeti-la e, em seguida, pronunciar as suas sílabas pausadamente, depois as letras e, em seguida, repeti-la novamente.

\section{Considerações finais}

Não temos ainda condições de avaliar sobre a efetiva utilização do método Lições de Coisas no Espírito Santo, mas, de acordo com o relatório do inspetor escolar Bodart Júnior, de 14 de junho de 1919, o método intuitivo de leitura não era adotado adequadamente naquele Estado. Segundo o inspetor, os professores não sabiam que a cartilha era um prêmio para os alunos pelo seu desempenho em leitura. Por isso,

(...) a creança entra para a escola e se lhe exige immediatamente o livro como se já pudesse manejal-o sem o auxilio do mestre; é um erro e um erro imperdoável, mormente, quando o methodo exige que, durante os 4 primeiros mezes o ensino seja feito exclusivamente no quadro negro, devendo o professor formar sentenças, sempre de objectos conhecidos.

Considerava o inspetor que os professores deveriam ser levados para fazer curso na Escola Modelo para garantir uniformidade do método adotado no Espírito Santo. Mesmo que não tenhamos elementos para analisar a utilização efetiva do método nas salas de aula, podemos dizer que a sua adoção oficial foi essencial para ajudar a sustentar também, naquele Estado, a crítica aos antigos métodos de soletração e fônico. Ao sugerir o ensino da leitura a partir da unidade palavra, ele inaugurou uma tradição, apesar de conservar elementos importantes dos antigos métodos, como o ensino das letras e dos sons. Além disso, a sua adoção nas províncias brasileiras contribuiu para a produção de livros de leitura de marcha analítica, partindo de sentenças e de palavras. De acordo com Valdemarin (2004, p. 149), 
(...) um aspecto que merece consideração é a dificuldade a ser vencida pelos professores da época para o uso do manual elaborado por Calkins. Dada a sua forma de organização e exposição dos conteúdos a serem ensinados, o texto impõe aos professores um enorme trabalho de estudo e reorganização, para ser utilizado na sala de aula na sequência determinada pelo andamento da classe e pela diversidade de atividades ao longo do dia na escola.

Nesse sentido, o relatório de Bodart Júnior corrobora o que foi dito pela autora, pois, para ele, os professores não sabiam trabalhar todas as fases propostas para o desenvolvimento do método de leitura e introduziam imediatamente o livro, antes de trabalhar as palavras conhecidas das crianças no quadro negro e em ardósia.

Podemos salientar, conforme aponta Valdemarin (op. cit., p. 147), que o método de leitura proposto no manual é “(...) um exemplar do movimento de renovação pedagógica ocorrido no século XIX, uma vez que seus objetivos visam à aquisição da 'leitura inteligente', voltada para a compreensão das ideias contidas no texto". Porém, como verificamos, o trabalho de soletração permanece vinculado à escrita. Assim, se é possível perceber alguns avanços com relação à leitura, o mesmo não pode ser dito com referência à escrita.

Valdemarin (2004) assinala ainda que os trechos analisados por ela sobre os sons deixam dúvidas sobre se os elementos fônicos da linguagem devem ser subsequentes ao ensino de palavras. Entretanto, conforme aponta essa autora, com base no manual de Calkins (1956), o trabalho com os sons visa a acostumar o ouvido a eles e, também, educar a sua produção vocal. O trabalho de escrita, por sua vez, visa à aprendizagem das formas ou do traçado das letras e das palavras. Somente após esse aprendizado, as crianças aprenderão as sílabas. Nesse sentido, os estudos dos sons e, também, da escrita de letras, palavras e sílabas podem ocorrer em momentos anteriores ao do ensino da leitura. Entretanto, preferimos considerar que o ensino dessas três dimensões ocorre simultaneamente. Em nossa opinião, a palavra no método é a unidade essencial, porque é ela que permite associar os trabalhos de escrita e de leitura preconizados.

Apesar das escolas funcionarem em casas precárias e sem o material necessário, no final do Império, jornais, documentos oficiais, discursos políticos etc. proclamavam a educação como primeiro elemento da civilização, afirmando que dela dependia o futuro e a renovação da sociedade. Entretanto, na década de 1880, as condições de funcionamento das escolas públicas no Espírito Santo continuavam precárias. Nesse contexto, o discurso político educacional, que se ancorava na ideia de que a reforma educacional, essencial para a renovação, se faria pela mudança dos métodos e dos mestres, era bastante conveniente para os governos que diziam não ter recursos para investir na construção de prédios escolares, nem na compra de material necessário ao seu funcionamento. 


\section{Notas}

1. Segundo Monteverde (18[-], p. 5) o método simultâneo consistia “(...) em dividir as classes ou turmas, segundo as suas forças, e fazer seguir ao mesmo tempo a toda uma classe a mesma lição de leitura, escripta, calculo, etc., isto é, o Professor a cada um em voz alta, e os outros o vão seguindo em seus livros ou cadernos".

2. O método misto era praticado no Espírito Santo a partir da conciliação dos métodos individual, simultâneo e mútuo.

3. O método João de Deus concretizado na Cartilha Maternal ou Arte de Leitura é um método de ensino da leitura. Ele se difere dos antigos métodos de soletração, pois se baseia na leitura de palavras.

4. De acordo com Saviani (2007, p. 128), o método mútuo, também denominado monitorial ou lancasteriano, proposto pelos ingleses Andrew Bell e Joseph Lancaster, "(...) baseava-se no aproveitamento dos alunos mais adiantados como auxiliares do professor no ensino de classes numerosas".

\section{Referências}

BAKHTIN, M. Estética da criação verbal. São Paulo: Martins Fontes, 1992.

BARROS, D.L.P. Contribuições de Bakhtin às teorias do discurso. In: BRAIT, B. Bakhtin, dialogismo e construção do sentido. Campinas: Editora da UNICAMP, 2007. p. 27-38.

BERTOLETTI, E.N.M. Cartilha do povo e Upa, Cavalinho: o projeto de alfabetização de Lourenço Filho. Disponível em: <http/www.capes.br>. Acesso em: 15 dez. 2006.

BURKE, P. Variedades de história cultural. Rio de Janeiro: Civilização Brasileira, 2000.

CALKINS, N. Lições de coisas. Trad. de Rui Barbosa. Rio de Janeiro: Ministério da Educação e Saúde, 1956. (Obras completas, v. 13, t. 1).

GRAFF, H.J. Os labirintos da alfabetização: reflexões sobre o passado e o presente da alfabetização. Porto Alegre: Artes Médicas, 1994.

LOURENÇO FILHO, R. Prefácio. In: Calkins, N. Lições de coisas. Trad. de Rui Barbosa. Rio de Janeiro: Ministério da Educação e Saúde, 1956. (Obras completas, v. 13, t. 1).

MACIEL, F.I.P. Lúcia Casassanta e o método global de contos: uma contribuição à história da alfabetização em Minas Gerais. 2001. 179f. Tese (Doutorado) - Faculdade de Educação, Universidade Federal de Minas Gerais, Belo Horizonte. Disponível em: <http/ www.capes.br>. Acesso em: 15 dez. 2006.

MELLO, L.M.A.V. A alfabetização em Campo Grande/MS, pela voz de pessoas da 3ㅁ idade. 2002. 105f. Dissertação (Mestrado) - Universidade Católica Dom Bosco, Campo Grande. Disponível em: <http/www.capes.br>. Acesso em: 15 dez. 2006.

MONTEVERDE, E.A. Methodo facillimo para aprender a ler tanto letra redonda como a manuscripta no mais curto espaço de tempo possível. 16. ed. Disponível em: <http://www. 
redalfa.estudiantesunlu.com.ar/galerias/portugal/galmethodofacillimo1899/index. php?list=1\&page=1>. Acesso em: $18 \mathrm{dez}$. 2007.

MORTATTI, M.R.L. Os sentidos da alfabetização. São Paulo: unesp, 2000.

SANTOS, S.M. Histórias de alfabetizadoras brasileiras: entre saberes e práticas. 2001. Tese (Doutorado em Educação) - Universidade Católica de São Paulo, São Paulo. Disponível em: <http/www.capes.br>. Acesso em: 15 dez. 2006.

SAVIANI, D. História das ideias pedagógicas no Brasil. Campinas: Autores Associados, 2007.

SCOCUGLIA, A.C.C. A história da alfabetização política na PARAIBRAsIL nos anos sessenta. 1997. 352f. Tese (Doutorado) - Universidade Federal de Pernambuco, Recife. Disponível em: <http/www.capes.br>. Acesso em: 15 dez. 2006.

SILVA, M.V. História da alfabetização no Brasil: a constituição de sentidos e do sujeito da escolarização. 1998. Tese (Doutorado) - Instituto de Estudos da Linguagem, Universidade Estadual de Campinas, Campinas. Disponível em: <http/www.capes.br >. Acesso em: 15 dez. 2006.

SOARES, M.B. Alfabetização no Brasil: o estado do conhecimento. Brasília, DF: INEP, 1989.

SOARES, M.B.; MACIEL, F. Alfabetização. Brasília, DF: MrC/Inep/ COMPED, 2000.

TRINDADE, I.M.F. A invenção de uma nova ordem para as cartilhas: ser natural, nacional de mestra. Queres ler? Bragança Paulista: EDusf, 2004.

VALDEMARIN, V.T. Estudando as lições de coisas. São Paulo: Autores Associados; FAPESP, 2004.

\section{Outras fontes}

ESPÍRITO SANTO (Província). Regulamento da Instrucção Publica da Província do Espírito-Santo. 15 set. 1882.

A PROVINCIA do Espirito-Santo, Vitória, n. 3, 19 mar. 1882a.

A PROVINCIA do Espirito-Santo, Vitória, n. 4, 22 mar. 1882b.

A PROVINCIA do Espirito-Santo, Vitória, n. 5, 24 mar. 1882c.

PORTO, L. A instrução. Espirito-Santense, Vitória, p. 3, 3 jun. 1886.

Recebido em julho de 2008.

Aprovado em outubro de 2008. 